\title{
Reinventando a história: Lincoln Gordon e as suas múltiplas versões de $1964^{1}$
}

\author{
Reinventing history: Lincoln Gordon
}

and his multiple versions of 1964

James N. Green*

Abigail Jones ${ }^{* *}$

Resumo

Lincoln Gordon, embaixador dos Estados Unidos no Brasil, esteve no centro das operações norte-americanas que apoiaram o golpe de Estado de 1964, desde a coordenação das conexões entre Vernon Walters e os conspiradores militares, até o lobby por uma força-tarefa naval dos Estados Unidos que interviria no caso da explosão de uma guerra civil entre forças pró e anti-Goulart. Apesar disso, naquele momento, e nos anos seguintes, Gordon insistiu em que o golpe de Estado tinha sido "100\% brasileiro". Através de documentos do Departamento de Estado norte-americano, discursos de Gordon, testemunhos orais, e de uma entrevista em 2005 com o embaixador, este artigo analisa as diversas justificativas que Gordon ofereceu ao longo dos últimos quarenta anos para explicar por que apoiou a derrubada de Goulart e concedeu suporte incondicional ao novo regime militar.

Palavras-chave: Lincoln Gordon; golpe de 1964; Operação Brother Sam.

\begin{abstract}
U.S. Ambassador Lincoln Gordon was at the center of U.S. operations that supported the 1964 coup d'etat, from coordinating connections through Vernon Walters with the military conspirators to lobbying for a U.S. naval task force that could intervene should a civil war break out between pro and anti-Goulart forces. At the time, and in the following years, Gordon, however, insisted that the coup d'etat was " 100 percent Brazilian.” Using U.S. State Department documents, Gordon's speeches, oral histories, and a 2005 interview with the former ambassador, this article analyzes the changing justifications that Gordon has offered over the last forty years to explain why he supported the overthrow of Goulart and gave unconditional support to the new military regime.

Keywords: Lincoln Gordon; 1964 coup d'etat; Operation Brother Sam.
\end{abstract}

\footnotetext{
* Professor de História do Brasil, Brown University. Presidente do New England Council on Latin American Studies. Department of History Box N - Brown University. Providence, RI 02912. james_green@brown.edu.

${ }^{* *}$ a/c James N. Green, Department of History Box N - Brown University. Providence, RI 02912. jones.abbie@gmail.com.
} 
Nós estamos tomando medidas complementares com os patrocínios disponiveis, visando colaborar com o fortalecimento das forças de resistência. Elas incluem suporte sigiloso para comícios pródemocracia (a próxima grande manifestação será no dia 2 de abril no Rio, e outras estão sendo programadas), discreta referência ao fato de o USG [United States Government] estar profundamente interessado nos eventos, e encorajamento [do] sentimento democrático e anticomunista no Congresso, nas Forças Armadas, nos grupos de estudantes e líderes sindicais simpáticos à política norte-americana, na Igreja e no mundo dos negócios. Num futuro próximo, poderemos requisitar modestos fundos suplementares para outros programas sigilosos de ação.

Telegrama do Embaixador dos EUA, Lincoln Gordon, para Washington (DC), 27 mar. $1964^{2}$

O movimento que derrubou o Presidente Goulart era 100 por cento - enão 99,44-mas 100\% um movimentopuramente brasileiro... Nem a Embaixada Norte-Americana, nem eu, pessoalmente, tivemos qualquer participação no processo.

Ex-Embaixador dos EUA para o Brasil, Lincoln Gordon, Audiência do Senado dos EUA, 7 fev. $1966^{3}$

Em 1974, Phyllis R. Parker iniciou um programa de Mestrado na Lyndon B. Johnson School of Public Affairs, na Universidade do Texas, em Austin. "Eu havia trabalhado no governo como assistente social, e como administradora na Texas Social Workers' School. Estava exausta, então fui para a pós-graduação", ela recordaria trinta anos mais tarde. ${ }^{4}$ Seus interesses eram política externa e educação, e precisou fazer um estágio e escrever uma dissertação de mestrado para titular-se. Por sugestão de seu marido, visitou a Biblioteca Presidencial Lyndon B. Johnson em busca de algum material que pudesse ser útil:

Eu estava interessada no Chile (porque meu marido tinha crescido lá), Peru ou Brasil. Eles me disseram que o governo brasileiro tinha passado por mudanças, e haveria disponibilização de documentos até então inacessíveis à consulta. Eu imaginei que seriam papéis sobre economia e política com gráficos, o que não 
parecia muito interessante, mas pensei que poderia consultá-los. Disseram: "Volte amanhã, e informaremos o que temos aqui".

Ela voltou no dia seguinte, e o arquivista informou-lhe que a biblioteca possuía um grande fundo de documentos referentes ao Brasil e recentemente liberados ao acesso público.

"O que isso significa?" Eles responderam que eu poderia solicitar sua abertura. "Eu poderia requisitar todos os documentos?" Disseram que sim, e eu assinei alguns papéis. Então, parti para Washington (DC), para trabalhar com a congressista Barbara Jordan, o que parecia muito mais interessante.

Ao retornar a Austin no final do verão, seu orientador recomendou a leitura da obra de Thomas E. Skidmore, Politics in Brazil, para que aprendesse sobre a história do Brasil em meados do século XX. ${ }^{5}$ Ela iniciou, então, o exame da referida documentação:

De início, olhei para os papéis pensando em apenas acrescentar algo ao que Skidmore tinha escrito. À medida que os lia, pensava sobre o porquê de Skidmore não ter incluído as informações em seu livro. Teria ele guardado para o final? Consultei ainda o livro de John Dulles e constatei, nesse meio tempo, que eles não as conheciam. ${ }^{6}$

Tratava-se da Operação Brother Sam, idealizada por Gordon e integrantes do Estado Maior, visando oferecer apoio militar e logístico para as forças anti-Goulart. Desde 1964, a esquerda brasileira acusava o governo dos Estados Unidos de ter apoiado ativamente as forças armadas quando estas depuseram o governo de Goulart. ${ }^{7}$ Phyllis Parker encontrara as provas de que a esquerda estava certa: altos funcionários do governo norte-americano tinham mentido acerca do envolvimento de Washington nos eventos de $1964 .^{8}$

Percebendo ter encontrado, como o historiador Richard Graham lhe disse, um "pote de ouro", Phyllis viajou para Boston para pesquisar na Biblioteca Presidencial John F. Kennedy:

Eu fiquei ali poucos dias, peguei alguns documentos, e fui para Washington para entrevistar Lincoln Gordon no Instituto Brookings ... Quando ele viu os documentos, pensou que a estória estivesse encerrada e que precisava fazer o melhor para contornar a situação. A verdade é que a estória não tinha acabado, e 
eu não entendia algumas coisas. À medida que ele falava, eu compreendia os documentos.

Ironicamente, Gordon acabou expondo o código do Departamento de Estado e ajudou Phyllis a decifrar as abreviações, referências e a obscura linguagem burocrática presente no material que ela tinha coletado. Ele a mandou à Central Intelligence Agency (CIA) para falar com o diretor Vernon Walters, que servira como adido militar norte-americano antes do golpe e atuara como ligação entre o governo dos Estados Unidos e os oficiais militares envolvidos na conspiração para derrubar o governo de Goulart.

Eu era uma jovem inocente de 27 anos. Ele [Walters] perguntou-me quais questões específicas eu tinha para perguntar. Eu não compreendia os documentos que tinha, então indaguei sobre ações sigilosas. Ele disse que elas existiam por todo lugar, o que não era muito esclarecedor... Perguntei sobre a presença de uma força-tarefa naval e ele respondeu: “Oh, isso foi apenas para exibir a bandeira norte-americana e estimular a estabilidade. Estaríamos lá para ajudar a retirada de norte-americanos, caso explodisse uma guerra civil". Naquele tempo, eu não sabia que, ao fim dos documentos, havia uma indicação - em acrônimo de que a força-tarefa tinha capacidade nuclear.

Em 1977, a Editora Civilização Brasileira publicou a dissertação de mestrado de Phyllis Parker sob o título 1964: o papel dos Estados Unidos no golpe de Estado de 31 de março, editado dois anos mais tarde em inglês como Brazil and the Quiet Intervention, $1964 .{ }^{9}$ É uma breve monografia, com cerca de cem páginas. Não obstante, revela uma história importante e até então não contada. No seu prefácio, Parker coloca a contradição entre os valores de justiça, igualdade e liberdade política, tal como defendidos pelos founding fathers dos Estados Unidos, e as políticas externas de Washington:

O programa de ação norte-americano parece estruturado para beneficiar os Estados Unidos - política, econômica e militarmente - mas, ao que tudo indica, sem maior consideração pelo impacto de seus empreendimentos sobre a integridade das instituições de outros povos. Segundo esse critério, os direitos reivindicados pela Declaração da Independência soam cada vez mais como princípios que se aplicam somente aos Estados Unidos e seus cidadãos, frequentemente à custa do sacrifício desses mesmos direitos em outras nações. (Parker, 1977, p.11) 
Os documentos que Phyllis Parker usou apontavam Lincoln Gordon como a figura central de todas as análises de apoio governamental dos Estados Unidos à conspiração militar e o imediato suporte ao regime militar instaurado com o golpe de Estado de 31 de março de 1964. Uma conversa na Casa Branca, no dia 30 de julho de 1962, entre o embaixador norte-americano Lincoln Gordon, o sub-secretário para Assuntos Interamericanos Richard Goodwin, e o presidente John F. Kennedy, aproximadamente dois anos antes do golpe, indica claramente as intenções de Washington no Brasil. Referindo-se às posições dos militares em relação a Goulart, Gordon disse:

- Creio que uma de nossas tarefas mais importantes consiste em fortalecer a estrutura militar. É preciso deixar claro, porém com discrição, que nós não somos necessariamente hostis a qualquer tipo de ação militar, contanto que fique claro o motivo...

O embaixador não pôde concluir sua frase, pois foi interrompido por Kennedy, que completou:

- Contra a esquerda.

Gordon, então, prossegue um tanto quanto exasperado:

— Ele [Goulart] está entregando o maldito país aos...

Kennedy completa novamente:

- Aos comunistas.

Ao longo da conversa, Goodwin chega a arriscar:

- ... nós podemos muito bem querer que eles assumam o poder até o final do ano, se puderem. ${ }^{10}$

Embora parte dos planos dos Estados Unidos para o Brasil tenha vindo à tona em transcrições e telegramas confidenciais e de acesso até então restrito, como no exemplo aqui citado, ainda há muito a esclarecer sobre o envolvimento norte-americano no golpe. Como muitos documentos - tanto brasileiros quanto norte-americanos - referentes a esse período permanecem inacessíveis, há uma nuvem cinzenta que encobre os estudos sobre o assunto. 
Por isso, o embaixador Gordon pôde, durante o transcurso de sua carreira, driblar a exposição dos detalhes daqueles acontecimentos.

Gordon recusou-se a refletir sobre o seu envolvimento no Brasil, com a intenção de entender suas ações e tirar conclusões. Ele optou, continuamente, por justificar o ocorrido em março de 1964. Este texto mostrará como Gordon modificou seu discurso, com o passar do tempo, para justificar suas ações no passado. Analisaremos, primeiramente, as preocupações que motivaram seu apoio ao general Castelo Branco e os outros conspiradores. Em seguida, examinaremos o envolvimento indireto dos Estados Unidos no golpe militar e a Operação Brother Sam. Concluiremos com sua análise sobre a natureza do regime militar.

Cada parte do texto contextualizará brevemente o evento em questão. Comentaremos a percepção de Gordon sobre os fatos, na época em que eles ocorreram, e, finalmente, apresentaremos as novas versões da história que ele construiu para preservar seu legado. Acompanhando o discurso diacrônico de Gordon, poderemos compreender melhor como o embaixador entende sua própria história e a história do Brasil. É também uma oportunidade para refletir sobre a política externa dos Estados Unidos para o Brasil e o restante da América Latina ao longo do século XX.

\section{Anticomunismo e a Guerra Fria}

Lincoln Gordon, estudante laureado em Harvard, ganhou uma bolsa Rhodes para fazer o seu doutorado em economia na Universidade de Oxford, Inglaterra, na década de 1930. Dividiu sua longa carreira entre a academia e o governo. Com o fim da Segunda Guerra Mundial, Gordon trabalhou como diretor da Missão do Plano Marshall, em Londres. Em seguida, assumiu o posto de Assuntos Econômicos da embaixada norte-americana. De volta aos Estados Unidos, lecionou Política em Harvard. Em 1961, foi nomeado embaixador no Brasil, por Kennedy, após ter participado da formulação da Aliança para o Progresso. Deixou o Brasil em 1966, para assumir o posto de sub-secretário de Estado para Assuntos Interamericanos, durante a presidência de Johnson, e, dois anos depois, foi indicado presidente da Universidade Johns Hopkins, em Baltimore. ${ }^{11}$

Para compreender a relação de Gordon com o Brasil durante o período em que foi embaixador, é preciso enquadrá-la no contexto da Guerra Fria. Conforme entrevista concedida por Thomas E. Skidmore: "Lincoln Gordon era realmente um produto da Guerra Fria, e sua missão era, como ele mesmo 
afirmou, garantir que o Brasil não se tornasse comunista” ${ }^{12}$ Como acadêmico em Oxford, Gordon foi testemunha privilegiada dos trágicos acontecimentos que levaram à Segunda Guerra Mundial. A experiência nazista fortaleceu sua convicção de que as ameaças à civilização ocidental deveriam ser aniquiladas, sentimento que estendeu ao comunismo, com a emergência da Guerra Fria.

Assim como muitos de seus pares, Gordon via o mundo em branco e preto: se um país não estava alinhado com os Estados Unidos, era aliado da União Soviética. Consequentemente, as preocupações demonstradas por Gordon em relação ao clima político brasileiro, enquanto esteve à frente da embaixada, refletem esses valores. Por exemplo, Gordon refere-se ao golpe que usurpou o mandato legal de Goulart como "Revolução", utilizando a mesma terminologia dos militares. Os conspiradores são chamados de democráticos, apesar de seus propósitos extralegais. Infelizmente, Gordon não reavaliou sua visão míope do golpe ao longo da sua carreira. Desde 11 de setembro de 2001, Gordon teve sua posição reforçada pela retórica antiterrorista prevalecente no governo Bush e pela perigosa tendência de transferir para a política a lógica simplista do amigo-inimigo. Nem sempre quem não está com você, está com os "inimigos", ou vice-versa.

João Goulart governou o Brasil durante um período de intensa agitação social. Contando mais com seu carisma do que com o apoio institucional, Goulart esforçou-se para manter o equilíbrio entre todas as facções da sociedade. No entanto, a radicalização de correntes dentro dos partidos políticos e a polarização das classes sociais mostrou-se uma combinação muito volátil para as suas manobras políticas. Goulart tentou consolidar seu mandado popular em meio a hiperinflação, débito fiscal, problemas na balança de pagamentos, produção em baixa, descontentamento dos trabalhadores e do campesinato, conspiração da direita e intervenção clandestina dos Estados Unidos em assuntos internos do país. Diante da pressão decorrente da crise financeira e do impasse político no Congresso, o presidente deu uma guinada à esquerda nos primeiros meses de 1964. Sua retórica ambígua de reformas de base estremeceu o frágil equilíbrio político brasileiro, com a direita tentando manter seu status quo, os centristas e a esquerda moderada desapontados com a indecisão de Goulart, e a esquerda radical exigindo mudanças mais substanciais.

Numa correspondência enviada ao secretário de Estado Dean Rusk, no dia 12 de agosto de 1963, Gordon explicita seu medo de um iminente golpe do presidente Goulart que, de acordo com a sua percepção, seria sucedido pela tomada do poder pelos comunistas. Gordon acreditava que esse processo político teria duas etapas: 
Ponderando as evidências com o máximo de objetividade possível, parece-me cada vez mais claro que o objetivo de Goulart é perpetuar-se no poder através de uma repetição do golpe de Vargas em 1937, instaurando um regime semelhante ao peronismo, com seu extremo nacionalismo antiamericano. O perigo da tomada de poder pelos comunistas decorre da total incompetência de Goulart para compreender ou resolver sérios problemas econômicos, administrativos, e outros quaisquer. No caso de Goulart servir como testa-de-ferro para estabelecer um regime autoritário, ele poderá facilmente ser posto de lado, como o general Naguib no Egito, e abrir caminho para algum Nasser comunista. ${ }^{13}$

Para reforçar sua tese, Gordon fez um relato enviesado da situação política brasileira. Ele alegou que Goulart tinha se engajado em "uma guerra aberta ou secreta contra [o Congresso, as Forças Armadas, a imprensa, governadores poderosos, e conselheiros moderados, e os Estados Unidos]", durante a segunda metade de $1963 .{ }^{14} \mathrm{O}$ telegrama mencionava episódios nada convincentes para comprovar essa hipótese. Gordon listou o tratamento de Goulart à questão da reforma agrária, a maneira como ele lidou com o inquérito aberto contra o Instituto Brasileiro de Ação Democrática, e sua decisão de estabelecer unidades militares adicionais em Brasília, como claras evidências da intenção de Goulart de desacreditar o Congresso. Gordon via a remoção do general Amaury Kruel do Ministério da Guerra, a promoção de um contingente de novos oficiais identificados com a esquerda radical, e a substituição de comandantes militares hostis a Goulart como indícios de que o presidente estava iniciando uma guerra contra o Exército.

Gordon julgava que Goulart estava censurando a mídia e influenciando a opinião pública através de entidades financeiras governamentais, o que prejudicava a liberdade de imprensa. Além disso, ele "projetava Arraes e minava não apenas Lacerda e Adhemar [de Barros], mas todos os governadores de centro-direita e centro-esquerda", o que deixava claro que o desejo de Goulart, segundo Gordon, era enfraquecer os governadores e fortalecer a centralização do poder em suas mãos. Ao substituir conselheiros moderados por "adolescentes irresponsáveis, simpatizantes e prováveis comunistas", Goulart demonstrava que tinha deixado a esquerda infiltrar seu governo. E, finalmente, "atacando a política externa norte-americana ao abandonar o Plano Trianual, negando-se a firmar compromisso com a American and Foreign Power Company (AMFORP) e os acordos com a Dantas-Bell, além de lançar ou colaborar para uma campanha contra mim [Gordon]", Goulart deixava claro 
seu ímpeto antiamericano. Cada um dos exemplos aqui fornecidos apontava para um cenário no qual o presidente iria consolidar seu poder ditatorial. ${ }^{15}$

O Bureau of Intelligence and Research (INR) do Departamento de Estado subsequentemente avaliou as recomendações de Gordon. Após revisar atentamente o telegrama do embaixador, o INR concluiu que:

definitivamente não parece, pela análise destas seis áreas, que Goulart está prestes a estabelecer um regime autoritário no Brasil... pelo contrário, as evidências disponíveis levam a crer que ele simplesmente pretende terminar seu mandato, e entregar o cargo a um sucessor legitimamente eleito em janeiro de $1966 .{ }^{16}$

Enquanto Gordon se esforçava para demonstrar que a retórica reformista de Goulart era apenas retórica, e não tinha a intenção de ser construtiva, o INR tirava conclusões bem diferentes. Os analistas do Departamento de Estado viam uma crescente "consciência democrática entre o povo brasileiro, o fortalecimento de elementos democráticos em todos os setores da sociedade, e uma relativa fraqueza dos comunistas e seus simpatizantes" ${ }^{17}$

Há várias interpretações sobre os propósitos de Goulart durante o último ano em que ele esteve no poder. A hipótese mais consistente é que ele procurou consolidar seu lugar na história brasileira como herdeiro de Vargas, implementando as reformas de base a fim de angariar apoio para o Partido Trabalhista Brasileiro (PTB). Acreditar que o único objetivo de Goulart era acumular poder para se transformar num ditador é desconsiderar o leque de alternativas que o presidente tinha ao seu dispor naquele período.

Sem sombra de dúvidas, a posição de Gordon era vista com bons olhos pelo governo norte-americano. Ralph A. Dungan deixou isso bem claro no memorando que enviou ao presidente Kennedy, em 28 de agosto de 1963:

Como você verá no anexo, existem opiniões diferentes sobre a natureza do problema no Brasil e, consequentemente, sobre como cada um se posiciona sobre isso. Eu acho que Linc [apelido de Gordon] tende a ser um pouco mais emocional e se ofende facilmente com possíveis ataques à sua integridade, porém eu acredito mais na visão dele sobre Goulart e sua administração do que na análise da INR, que atribui muito das aberrações de Goulart ao seu extremo nacionalismo. ${ }^{18}$

Certamente, as principais conclusões de Gordon e sua avaliação geral da situação política brasileira eram perfeitamente compatíveis com a visão de mundo - impregnada pela atmosfera da Guerra Fria - dos políticos de Wa- 
shington naquele período. Não é sem motivos que o governo norte-americano mostrou-se tão amistoso às suas ideias.

Assim como o clima político nos Estados Unidos evoluiu com a passagem do tempo, Gordon também teve de revisar regularmente suas interpretações sobre o agravamento da crise política no Brasil entre o final de 1963 e o início de 1964. Utilizando sua análise de agosto de 1963 como referência, descreveremos como ele reformula seus argumentos para justificar as razões pelas quais aprovou entusiasticamente a instauração da ditadura em 31 de março de 1964.

Ao longo de sua carreira, a conceitualização de Gordon sobre a ameaça iminente de golpe no país oscila constantemente. Ora parece acreditar que se tratava apenas de um golpe populista, ora ele parece convicto de que os comunistas iriam tomar o poder num segundo momento. Durante o final da década de 1960, Gordon matizou suas acusações a Goulart e não fez menção às questões que tanto o preocupavam em 1963. Nos anos 70, a ameaça de um golpe que desencadearia uma guerra civil no Brasil fortificou-se na memória de Gordon como sua principal preocupação durante a etapa final do mandato de Goulart. Em 1990, o ex-embaixador retoma algumas preocupações anteriormente expressadas em seu telegrama para Dean Rusk. Em suas tentativas mais recentes de justificar o apoio norte-americano às forças anti-Goulart, Gordon, num primeiro momento, ecoa a tese do golpe e, a seguir, acrescenta a ideia do complô comunista.

O que chama a atenção na evolução do discurso de Gordon é que ele nunca usa as evidências que apresentou em 1963, e que apontavam para um golpe, para justificar sua posição posterior. Se inicialmente o embaixador sustentava suas hipóteses recorrendo a eventos ocorridos principalmente entre outubro de 1963 e março de 1964, com o passar do tempo ele muda suas referências históricas, incorporando, por exemplo, a "Revolução Constitucionalista" de 1932 e a tentativa de golpe em 1961 à sua análise, eventos que não estavam presentes nos seus argumentos de 1963. Fica evidente, na análise que faremos a seguir, que Gordon reconstruiu sua linha de defesa em decorrência das críticas que recebeu sobre suas informações pouco confiáveis de 1963.

\section{LINHAS DE DEFESA}

Em 1966, Gordon depôs no Comitê de Relações Exteriores do Senado norte-americano, logo após ser nomeado sub-secretário de Estado para Assuntos Interamericanos. Durante sua exposição, os senadores solicitaram que 
ele comentasse a situação política brasileira durante o período em que esteve à frente da embaixada. Gordon então declara: "com o rumo que as coisas haviam tomado, acredito que haveria uma tragédia muito séria e talvez muito prolongada na nação mais importante da América Latina". ${ }^{19}$ Seu depoimento é notável, pois não menciona em nenhum momento a inevitável tomada do poder pelos comunistas no Brasil. Em vez disso, Gordon ressalta a inevitabilidade de um golpe no qual Goulart criaria uma ditadura personalista nos moldes da que foi criada por Perón ou por Vargas durante o Estado Novo. Sob juramento, Gordon afirmou:

com o início da quarta fase do mandado - de julho de 1963 até o fim do regime, em março de 1964 - ficou cada vez mais claro que a intenção do presidente era, de fato, subverter o regime em favor de uma ditadura personalista, implementada anteriormente por Perón e Vargas, seu mentor, em 1945. Era um tipo de ditadura populista, como a de Perón, como a de Vargas, com um verniz protetor [que oferecia] grande benefício para as massas. Ninguém sabe o que ele teria feito se, de fato, tivesse sido bem sucedido. Mas que ele tinha essa intenção em mente eu acredito, e certamente muitos brasileiros responsáveis também acreditavam firmemente nisso nos últimos meses de 1963 e, particularmente, nos três primeiros meses de $1964 .{ }^{20}$

Gordon então reforça sua conviç̧ão mencionando algumas atitudes de Goulart, tais como a declaração de estado de sítio em outubro de 1963; a tentativa abortada de prender Carlos Lacerda no mesmo mês; ${ }^{21}$ sua leniência com Brizola e com a esquerda radical; e sua utilização de decretos para expropriar terras em março de 1964, o que, segundo Gordon, "não tinha base nas leis nem na Constituição". ${ }^{22}$ Excluindo-se a tolerância de Goulart com Brizola e a esquerda do PTB, cada um dos exemplos de Gordon eram incidentes que ocorreram após o envio de seu telegrama para Washington. ${ }^{23}$

Esse depoimento não corrobora sua versão dos eventos de 1963, além de utilizar argumentos anacrônicos para justificá-la. Um ano mais tarde, Gordon defende novamente a inevitabilidade do golpe populista em uma conferência sobre "Intervenção e Estados em Desenvolvimento", na Universidade de Princeton:

... nós aprovamos a revolução brasileira por nossa convicção de que o presidente estava planejando acumular poderes ditatoriais no padrão de seus dois mentores, Getúlio Vargas e Juan Perón. Para sustentar essa convicção nós temos bem 
mais evidências sólidas do que acusações na imprensa brasileira antigovernista. Eu nunca tive motivos para duvidar disso... ${ }^{24}$

Se as evidências às quais Gordon está se referindo são aquelas que ele citou em seu depoimento no Congresso, teremos de continuar refletindo sobre os motivos reais que o levaram a suspeitar de que Goulart buscava essencialmente a centralização do poder em suas mãos, hipótese essa refutada pela INR.

No final de década de 1970, Gordon re-conceitualizou novamente sua proposição inicial sobre as intenções de Goulart. Com a liberação à consulta pública de documentos relacionados ao plano de contingência dos Estados Unidos para o golpe militar de 1964, Gordon teve de retomar essa questão para se justificar perante a opinião pública, tanto norte-americana como brasileira. Numa entrevista concedida por telefone ao jornal The New York Times, em 1976, Gordon enfatizou que, depois de estudar a guerra civil de 1932 no Brasil, e tendo em vista o "rápido crescimento das forças comunistas e outras forças de esquerda sob o comando de Goulart, em março de 1964", desenvolveu a hipótese de uma guerra civil com forças brasileiras igualmente divididas. ${ }^{25}$ Nessa entrevista Gordon não mencionou nem o golpe de Goulart, nem $\mathrm{o}$ assalto ao poder pelos comunistas.

Um ano depois, Gordon voltou à sua linha de defesa habitual, alegando que Goulart desejava seguir os passos de Perón e Vargas, agregando a hipótese da guerra civil:

Minha conviç̧ão era a de que Goulart estava determinado a transformar-se num ditador comunista, à imagem de seus dois heróis políticos, Getúlio Vargas e Juan Perón, e de que isso seria irreversível se ele continuasse na presidência. Cheguei a compartilhar essa ideia, especialmente depois do discurso de Goulart na sexta-feira de 13 de março, no comício para uma imensa aglomeração de extrema esquerda. A hipótese de guerra civil surgiu parcialmente da precedente Revolução Constitucionalista de 1932, deflagrada por São Paulo contra Vargas, e parcialmente de crises mais recentes, como a de agosto de 1961, que levou à renúncia de Jânio Quadros. ${ }^{26}$

Até esse momento, o argumento de Gordon baseava-se na ideia de que Goulart estava buscando poderes ditatoriais, e, consequentemente, a conflagração de uma guerra civil era inevitável. Em 1990, Gordon reformulou esse argumento para inserir ideias previamente articuladas por ele em agosto de 1963.

Nesse ano, ele escreve uma resenha criticando o livro de Ruth Leacock, 
Réquiem for Revolution: the United States and Brazil, 1961-1969. ${ }^{27}$ No ensaio ele comenta:

O que eu temia era um golpe de duas etapas no qual primeiramente Goulart assumiria o poder nos moldes de Perón ou Vargas e em seguida seria substituído por uma figura com personalidade mais forte - como aconteceu no Egito com Naguib e Nasser. Esse sucessor, por sua vez, provavelmente imitaria Fidel Castro, buscando aliança e apoio na União Soviética. As evidências que sustentavam a primeira etapa do golpe não só eram convincentes naquele tempo, como foram reforçadas pelas memórias de Gorender e de Samuel Wainer, um amigo íntimo de Goulart e editor do jornal Última Hora. ${ }^{28}$

O abandono do Plano Trianual de Dantas-Furtado, em julho de 1963, a declaração de estado de sítio e o complô abortado para sequestrar Carlos Lacerda - ambos em outubro de 1963 — , além de uma política clara de apoio aos setores de esquerda dentro das Forças Armadas e dos sindicatos, convenceram Gordon, naquele tempo, de que Goulart iria tornar-se um ditador. Mas as evidências que ele apresenta para refutar Leacock têm pouco a ver com seus argumentos de 1963, e, além disso, Gordon não tem êxito na apresentação de elementos que sustentem a inevitabilidade de os comunistas tomarem o poder em 1964.

Recentemente, Gordon teve duas oportunidades para reelaborar suas percepções sobre a queda de Goulart. Em 2003, o embaixador veio a público novamente para justificar o apoio dos Estados Unidos na derrubada de Goulart, com a publicação de um dos capítulos do livro A segunda chance do Brasil: a caminho do primeiro mundo. ${ }^{29}$ Em 2005, ele nos concedeu uma entrevista em Washington.

A linha de defesa utilizada por Gordon no seu livro é muito parecida com aquela que ele utilizou em 1977. Menciona a Revolução Constitucionalista de 1932 e a tentativa de golpe em 1961 como exemplos de um padrão a partir do qual é possível inferir que a guerra civil era iminente no Brasil. Contudo, deve-se atentar que em 1932 a guerra civil foi rapidamente reprimida, e em 1961 a guerra civil foi evitada.

Em 2005, Gordon retomou suas conclusões de 1990, apresentando menos evidências consistentes e reconhecendo que suas conclusões eram meramente especulativas:

eu achava que havia uma grande possibilidade de um regime totalitário ... Num primeiro momento, certamente não seria um regime do partido comunista, em- 
bora os comunistas estivessem fortemente infiltrados nesse regime. Depois disso, é muita especulação. ${ }^{30}$

Em seguida, Gordon afirmou ter baseado suas conclusões em rumores que circulavam pelo país:

Todas as notícias de jornais diziam, eu não sei se nós tínhamos alguma confirmação definitiva, mas parecia provável à luz do que aconteceu na sexta-feira de 13 de março. Ele supostamente faria um comício por mês em cidades diferentes. O último comício supostamente seria no Primeiro de Maio, o tradicional Dia do Trabalho da esquerda radical, em São Paulo, a cidade com a maior concentração de sindicatos, a maior concentração de comunistas no país, e o maior colégio eleitoral. Se você revisasse a imprensa brasileira, veria todo tipo de rumores. A impressão geral era de que aquele comício seria o definitivo. No Primeiro de Maio ele anunciaria que estava assumindo plenos poderes, o que seria equivalente ao discurso de Vargas em 1937 [instaurando] o Estado Novo. As histórias soavam como se eles fossem percorrer um caminho que nós já conhecíamos, mas eu não tenho nenhuma informação privilegiada de como isso aconteceria. (Gordon, 3 ago. 2005)

Contradizendo completamente suas afirmações de 1967 de que "nós tínhamos bem mais evidências sólidas do que acusações na imprensa brasileira antigovernista", Gordon mostra os pés de barro de seu argumento. ${ }^{31}$

Gordon nunca menciona, no seu discurso diacrônico, os argumentos iniciais de 1963. Ele modifica levemente as conclusões com regularidade, mas nunca justifica as suas deduções de que Goulart estava engajado numa "guerra aberta ou secreta contra [o Congresso, as Forças Armadas, a imprensa, os governadores mais poderosos, os conselheiros mais moderados e os Estados Unidos]" como fez durante a segunda metade de 1963 no telegrama que enviou a Dean Rusk. ${ }^{32}$ Parece no mínimo duvidoso que Gordon tivesse evidências consistentes naquele tempo para substanciar suas conclusões. Em 2005, ele finalmente reconhece as limitação de seus argumentos, ao admitir que o golpe de duas etapas era meramente um exercício especulativo baseado em rumores. Ele teve de voltar aos fatos e recriar evidências concretas que justificassem historicamente seu apoio ao regime militar.

A operação secreta norte-americana, batizada de Brother Sam, era um plano de contingência concebido em 1964 para responder ao agravamento da crise política no Brasil. A operação incluía uma força-tarefa naval e abastecimento de petróleo, gasolina, e derivados, além de armas e munição para os 
conspiradores. ${ }^{33}$ Em 27 de março, Gordon alegava que essa ação dos Estados Unidos tinha como objetivo "garantir a vitória das forças amigas, mas não prestar apoio logístico ou participar militarmente da ação ... Nossa capacidade de mostrar comprometimento e um grau moderado de força com grande rapidez poderia ser crucial". ${ }^{34}$

Gordon negava que a Operação Brother Sam tivesse existido, até que a disponibilização ao público, em 1975, de inúmeros documentos da biblioteca presidencial Lyndon Baines Johnson tornaram sua versão insustentável. A partir de então ele tem negado veementemente que os Estados Unidos tenham desempenhado um papel direto no planejamento ou no financiamento do golpe. Gordon sustenta, desde 1964, quando o plano foi originalmente concebido, que a Operação Brother Sam tinha como finalidade "mostrar a bandeira norte-americana”. Quando sua existência veio a público, anexou-lhe um componente diplomático: evacuar os cidadãos norte-americanos no caso de uma guerra civil. Essa justificativa não é nem convincente nem plausível.

No depoimento prestado ao Senado norte-americano, em 1966, Gordon proferiu a famosa frase de que o movimento que derrubou Goulart era " $100 \%$ — não 99,44 - mas 100\% puramente brasileiro” e reiterou que nem ele nem outros funcionários do governo norte-americano estiveram envolvidos "ajudando, incitando ou participando" da derrubada de Goulart. ${ }^{35}$

Depois que documentos pertencentes à Operação Brother Sam vieram a público, Gordon nunca mais negou calorosamente o envolvimento norteamericano no golpe militar. Ele passou a usar uma linguagem mais matizada e focada em pontos específicos do plano de contingência, como fez em 1976, quando declarou que a CIA não desempenhou nenhum papel no golpe, "dirigindo-o ou financiando-o". ${ }^{36}$ Ele nunca esclareceu essa ambiguidade.

Quando a Operação Brother Sam veio à luz, em 1977, Gordon passou a focar seu discurso nos propósitos da operação, não em suas especificidades:

A força-tarefa não foi criada para uma intervenção militar, com força de combate. Ela foi criada para tornar possível uma forma de ação norte-americana limitada, em uma contingência hipotética específica, uma guerra civil com o Brasil dividido em linhas geográficas, com forças do mesmo tamanho, e com um dos lados reconhecido por nós. Dentro dessa hipótese, a força-tarefa teria tido três propósitos: (a) providenciar apoio logístico, especialmente em derivados de petróleo, para o lado que nós acreditávamos representar a moderação e a democracia; (b) desencorajar o outro lado mostrando a bandeira dos Estados Unidos em uma embarcação poderosa; e (c) ajudar se necessário na evacuação de cida- 
dãos americanos das regiões envolvidas no combate civil. (Gordon, jan. 1977, p.5, grifos nossos)

É curioso que, em 1977, Gordon relembre sua preocupação com a evacuação de civis norte-americanos do Brasil, já que isso nunca foi mencionado em nenhuma correspondência entre o embaixador e o secretário de Estado em 1964. Usar esse argumento em retrospecto chama a atenção. Se o contingente naval foi enviado ao Brasil para resgatar todos os norte-americanos no país naquele momento, isso nunca teria sido feito de uma maneira eficiente, dado o número de navios e a imensidão do Brasil. Em seu livro publicado em 2003, Gordon reitera sua já famosa posição:

no caso de uma guerra civil, eu acreditava que "mostrar a bandeira americana" serviria a dois propósitos: (a) pôr pressão psicológica em favor do lado antiGoulart; e (b) ajudar na evacuação de milhares de civis norte-americanos que viviam no Brasil ou estavam visitando quaisquer de suas regiões. (Gordon, 2002, p.109)

Nesse período, o embaixador parecia ter se convencido de que, em março de 1964, estava preocupado com a vida dos cidadãos norte-americanos no Brasil. Isso pode ser plausível. Essa preocupação, porém, nunca foi mencionada em 1964, mas capciosamente tornou-se uma linha de defesa para Gordon, depois que a opinião pública norte-americana tomou conhecimento da existência da operação naval.

O próprio Gordon expõe a fragilidade do seu argumento. Na entrevista que nos concedeu em 2005, conta como seu filho passou o ano de 1963-1964 lecionando no Brasil, antes de ingressar na faculdade, nos Estados Unidos. Ao ser questionado sobre sua possível preocupação com a segurança do filho, em março de 1964, ele respondeu:

Não, eu não acho que essa questão surgiu. Não havia nenhum grande antiamericanismo ... era bem claro que não era como o Iraque naquele momento ... Eu não me lembro de isso ter passado pela minha cabeça ... Nós realmente não tínhamos a sensação de distúrbio civil. (Gordon, 3 ago. 2005)

Gordon, então, começa a descrever o plano de evacuação:

Nós tínhamos um plano de mostrar a bandeira e também evacuar nossos civis, se fosse o caso, o que teria sido uma grande tarefa. Eu acho que havia 15 mil. 
Teria sido uma grande operação. E obviamente isso seria feito em meio a hostilidade, nós nunca tivemos a sensação ... mas a guerra civil não era uma ameaça política à comunidade norte-americana. (Gordon, 3 ago. 2005)

A ênfase atual do embaixador na evacuação dos cidadãos norte-americanos talvez sirva para reforçar o legado que ele buscou construir para si mesmo. Porém, isso não nos ajuda a compreender quais as motivações de Washington ao enviar aquela força-tarefa ao Brasil.

\section{DEFENSOR ETERNO DO GOLPE DE 1964}

Gordon nunca questionou sua decisão de apoiar o general Castelo Branco e os conspiradores. Mesmo diante do fato de que isso levou a uma ditadura que durou 21 anos, Gordon defende veementemente sua posição histórica. Recentemente, em 2005, o embaixador declarou: "Eu continuo acreditando na devoção de Castelo à ideia de restaurar rapidamente as instituições democráticas ... Acho que sua devoção era verdadeira" (Gordon, 3 ago. 2005). Em 1966, em depoimento ao Senado, disse estar convencido de que "o principal propósito da revolução de 31 de março e $1^{\circ}$ de abril de 1964 era preservar, e não destruir a democracia no Brasil", complementando que "o histórico daquele período deixa isso claro". ${ }^{37} \mathrm{O}$ embaixador ainda elencou a manutenção da liberdade de imprensa e o funcionamento do Congresso, com a realização de eleições "livres", como indícios de um regime de exceção, e não de uma ditadura militar.

Em 1966, Gordon defendeu o Ato Institucional n² 2 (AI-2), promulgado no ano anterior, como necessário para "garantir a posse dos governadores eleitos em outubro de 1965, dois dos quais eram oponentes do regime" ${ }^{38} \mathrm{Em}$ 1967, ele reiterou essa posição, clamando energicamente que "está acima de qualquer suspeita o fato de que as práticas democráticas estão mais enraizadas no Brasil hoje, e as perspectivas de sua completa restauração e consolidação são bem maiores agora do que seriam se a revolução de 1964 não tivesse ocorrido" ${ }^{39}$ Em outubro de 1968 - dois meses antes de o Ato Institucional ${ }^{\circ}$ 5 (AI-5) ser promulgado - Gordon reconheceu a natureza semiautoritária do regime, mas intercalou suas críticas com referências positivas às conquistas obtidas pelos militares. Nessa ocasião, alegou que "em casos como o do Brasil, o caráter semiautoritário do regime é combinado com uma imprensa livre bastante crítica, Congresso eleito, e um conjunto de legislaturas estaduais e municipais, bem como vida política intensa". ${ }^{40}$ 
Gordon só se distanciou do governo brasileiro sob a forte pressão das denúncias internacionais contra as novas medidas arbitrárias após o AI-5. Em maio de 1969, quando assinou a petição condenando a aposentadoria compulsória de professores das universidades brasileiras, efetivada no mês anterior, Gordon comentou: "Minha objeção à remoção de professores é parte de minhas preocupações mais profundas sobre o uso arbitrário do poder pelos militares desde dezembro [de 1968]" ${ }^{41}$

No final de 1969, membros da oposição brasileira uniram forças com clérigos, acadêmicos e ativistas norte-americanos, e também com alguns brasileiros residentes nos Estados Unidos, para denunciar a tortura no Brasil. ${ }^{42}$ Em uma das primeiras campanhas publicou uma série de artigos em diversos jornais progressistas e liberais, documentando a expansão do uso da violência física contra os oponentes do regime. Um desses artigos - matéria de capa publicada em 24 de abril de 1970 na revista Commonweal, sob o título "Tortura no Brasil", assinado por Ralph Della Cava - afirmava a cumplicidade de Lincoln Gordon ao defender um regime que torturava seus cidadãos. ${ }^{43}$ Della Cava escreveu um texto enérgico, apontando diretamente o apoio do governo dos Estados Unidos ao regime. Gordon escreveu uma Carta ao Editor da referida revista, na qual usou seus argumentos de sempre para justificar sua defesa das forças que depuseram Goulart.

Gordon, então presidente da Johns Hopkins University, em Baltimore, Maryland, insistiu em que o Primeiro Ato Institucional foi uma "monstruosa mudança do princípio democrático básico", e clamou ter "cogitado uma retirada simbólica de Washington". ${ }^{44}$ Entretanto, considerando que Castelo Branco provavelmente seria eleito presidente e que o general seria "moderado e constitucionalista", rejeitou a ideia. Ao mesmo tempo, argumentou que "havia vários candidatos que falavam abertamente de si mesmos como 'Fidel Castros' do Brasil", trazendo o risco de que, tendo em vista o tamanho e a localização do país, "tal curso de eventos - evidentemente hipotético, mas não implausível - poderia levar toda a América Latina a regimes totalitários de esquerda". O ex-embaixador desviou-se de qualquer responsabilidade pela Caixa de Pandora que ajudou a abrir, a qual levou às flagrantes violações dos direitos humanos, em 1969.

Em resposta à carta de Gordon, Ralph Della Cava, na época professor de História da América Latina na City University of New York, em Queens, apontou que a tortura ocorrera no Brasil sob sua vista e que, na ocasião e ainda em 1969, o embaixador se recusava a pronunciar-se contra essa prática. Demonstrando que, em 1964, os jornais já faziam cobertura de casos de tor- 
tura contra os oponentes do novo regime, Della Cava argumentou: "é inconcebível que esses relatos públicos e oficiais não tenham alcançado o embaixador ou seu staff" ${ }^{45}$ Ele ainda indagou "em que bases a Embaixada do Rio formulou a política norte-americana a respeito da tortura, sem falar das decisões que levaram ao monumental aumento da ajuda dos Estados Unidos ao Brasil em 1964, 1965 e 1966”. Della Cava listou, então, uma longa série de violações dos direitos constitucionais e políticos ocorridos no Brasil enquanto Gordon era embaixador e, posteriormente, sub-secretário de Estado para Assuntos Interamericanos. O autor concluía que "a carta do dr. Gordon deve ser lida como um exemplo do que tem acometido a política externa dos Estados Unidos" (Della Cava, ago. 7, 1970, p.399).

Em 1977, Gordon buscou se distanciar do regime: "Pressões para restabelecer o governo constitucional ... continuaram no Brasil pelos próximos 13 anos, com retrocessos em 1965 e 1968, mas sem nunca terem sido abandonadas" (Gordon, jan. 1977, p.7). O retrocesso de 1965 ao qual ele se refere é a promulgação do AI-2, ainda sob a presidência de Castelo Branco. Gordon foi progressivamente recuando a data de sua desilusão com os militares brasileiros. Em 2005, disse que o regime militar mudou de natureza em 1965:

O segundo Ato Institucional foi a mudança decisiva ... Quem poderia imaginar ... Afinal de contas, o motivo do AI-2 foi o protesto dos jovens oficiais, a volta de Kubitschek, e a eleição de dois governadores [de oposição] totalmente inofensivos do ponto de vista da revolução. Eles foram usados como bodes expiatórios pela linha dura para encurralar Castelo Branco, me disseram, e então ... eu sabia que os meus amigos tinham perdido. (Gordon, 3 ago. 2005)

Mas as mudanças no discurso de Gordon sobre a natureza do regime militar, de democrático para semiautoritário e, finalmente, para ditatorial, nunca afetaram sua admiração pelo general Castelo Branco. Ele só concordou em denunciar o regime militar, no abaixo-assinado que condenava as aposentadorias compulsórias nas universidades brasileiras, em 1969, porque Castelo Branco já havia deixado a Presidência. Continuou equivocadamente defendendo a fé democrática do general, apesar de este ter assinado o AI-2, alegando que representantes da linha dura, como Costa e Silva, o pressionaram a tomar essa medida antidemocrática.

As mudanças no discurso do embaixador Lincoln Gordon nos ajudam a compreender como ele queria construir sua imagem histórica. Ao invés de reconsiderar a sua participação nos eventos de 1964, adotando uma postura 
mais sofisticada e imparcial desse período conturbado, preferiu justificar e defender seu passado. Prendendo-se aos parâmetros da Guerra Fria, Gordon se negou a reavaliar suas ações. As múltiplas versões dos eventos de março de 1964, que ele apresenta ao longo de sua trajetória política e intelectual, não são muito diferentes da sua formulação original. Recentemente, reiterou: "Eu não creio que pudesse ter feito algo diferente" (Gordon, 3 ago. 2005). Na realidade, o que mudou, ao longo dos anos, foram os argumentos utilizados por Gordon como desculpa para legitimar sua visão anticomunista e sua política golpista.

(Tradução: Adriana A. Marques)

\section{NOTAS}

${ }^{1}$ James N. Green é autor de Além do Carnaval: a homossexualidade no Brasil do século XX, São Paulo: Ed. Unesp, 2000, e Apesar de vocês: a oposição à ditadura brasileira nos Estados Unidos, 1964-85, São Paulo: Companhia das Letras, 2009. Abigail Jones é graduada com distinção em Estudos Latino-Americanos e História da Arte pela Brown University e, atualmente, é analista de pesquisa no programa de Economia e Desenvolvimento Global do Brookings Institute, em Washington (DC). Ela é co-editora de Climate change and global poverty: A billion lives in the balance? (Brookings Institute Press, 2009) e publicou recentemente Double jeopardy: what the global climate crisis means for the poor (Brookings Institute, 2009) e U.S. foreign assistance to Sub-Saharan Africa: a snapshot of previous U.S. priorities and recommendations for the Obama Administration (Global Views No. 9, Brookings Institute, 2008). Este artigo resulta do programa Brown University Undergraduate Training and Research Assistantship (UTRA), entre os meses de junho e agosto de 2006.

${ }^{2}$ Rio de Janeiro to State Department, Telegram, No. 48986, March 27, 1964, National Security File, Country File, Brazil, vol. 2, 3/65, Box 9, Lyndon B. Johnson Library.

${ }^{3}$ UNITED STATES SENATE. Committee on Foreign Relations, Nomination of Lincoln Gordon to be Assistant Secretary of State for Inter-American Affairs, $89^{\text {th }}$ Congress, $2^{\text {nd }}$ Session, Washington: GPO, February 7, 1966: 44.

${ }^{4}$ PARKER, P. R. Entrevista por telefone, concedida a James N. Green, 27 jul. 2005, notas. Todas as citações subsequentes de Parker são dessa entrevista.

${ }^{5}$ SKIDMORE, T. S. Politics in Brazil, 1930-1964: an experiment in democracy. New York: Oxford University Press, 1967. Nota do tradutor: No Brasil esse trabalho foi publicado sob o título Brasil, de Getúlio a Castelo, 1930-64. Rio de Janeiro: Ed. Saga/Paz e Terra, 1969.

${ }^{6}$ Parker referia-se a DULLES, J. W. F. Unrest in Brazil: political-military crisis, 1955-1964. Austin: University of Texas Press, 1970. 
${ }^{7}$ Ver, por exemplo, MOREL, E. O golpe começou em Washington. Rio de Janeiro: Civilização Brasileira, 1965.

${ }^{8}$ Marcos Sá Corrêa, jornalista brasileiro, examinou mais tarde os mesmos documentos e escreveu uma série de artigos, publicados no Jornal do Brasil (Rio de Janeiro), sobre as novas revelações ali contidas. Posteriormente, os artigos foram reunidos por ele em livro: CORRÊA, M. S. 1964: visto e comentado pela Casa Branca. Porto Alegre: L\&PM, 1977.

${ }^{9}$ PARKER, P. R. 1964: o papel dos Estados Unidos no golpe de Estado de 31 de março. Rio de Janeiro: Civilização Brasileira, 1977; Brazil and the quiet intervention, 1964. Austin: University of Texas Press, 1979.

${ }^{10}$ NAFTALI, T. (Org.). “Monday, July 30, 1962,” The presidential recordings, John F. Kennedy: the great crisis, volume one. New York: W. W. Norton and Company, 1997. p.1819.

${ }^{11}$ BLACK, J. K. “Lincoln Gordon and Brazil's Military Counterrevolution”. In: RONNING, C. N.; VANNUCCCI, A. P. Ambassadors in foreign policy: the influences of individuals on U.S.-Latin American Policy. New York: Prager, 1987. p.95-113.

${ }^{12}$ SKIDMORE, T. S. Entrevista concedida a James N. Green e Abigail Jones. Providence, Rhode Island, 28 jul. 2005. gravada.

${ }^{13}$ Ambassador Lincoln Gordon to Secretary of State Dean Rusk, 21 August 1963, No. 373, Brazil: August 1963, National Security File, John F. Kennedy Library. Na sua conclusão errônea predileta, Gordon aponta o exemplo dos dois ícones latino-americanos (Perón e Vargas), cuja ascensão ao poder coincidiu com a violenta repressão ao Partido Comunista em seus respectivos países. Teria sido mais adequado na perspectiva do embaixador - e mais convincente em termos da intervenção norte-americana - se Gordon tivesse feito uma comparação explícita com Fidel Castro, que permaneceu uma figura ambígua até 1961, quando se autoproclamou um "marxista-leninista". Por que a reticência em identificar Goulart com Castro? Gordon admitiu, em inúmeras ocasiões, saber que Goulart não era um comunista, assim como os Estados Unidos acreditaram, no momento da Revolução de 1959, que Castro era um democrata. A lógica apresenta-se imperfeita. De acordo com os cálculos de Gordon, Goulart assumiria o poder completo do país em 1º de maio de 1964 - Dia do Trabalho - em São Paulo, como ápice de uma série de manifestações iniciadas em 13 de março de 1964, no Rio de Janeiro, em frente ao Ministério da Guerra. Acreditava-se que, após assumir o poder ditatorial ao estilo de Perón e Vagas, tipicamente associados com a repressão da esquerda, seria deposto pelos comunistas. Apenas a paranoia da Guerra Fria poderia apresentar tal sequência de eventos como algo factível.

${ }^{14}$ Ambassador Lincoln Gordon to Secretary of State Dean Rusk, 21 August 1963, No. 373, Brazil: August 1963, National Security File, John F. Kennedy Library.

${ }^{15}$ Ambassador Lincoln Gordon to Secretary of State Dean Rusk, 21 August 1963, No. 373, Brazil: August 1963, National Security File, John F. Kennedy Library.

${ }^{16}$ Thomas L. Hughes to Mr. Martin, "INR Comments on Embassy Rio Telegram 373 Con- 
cerning the Brazilian Political Situation,” 29 August 1963, Brazil Security 1963, Presidential Files, John F. Kennedy Library.

${ }^{17}$ Thomas L. Hughes to Mr. Martin, "INR Comments on Embassy Rio Telegram 373 Concerning the Brazilian Political Situation,” 29 August 1963, Brazil Security 1963, Presidential Files, John F. Kennedy Library.

${ }^{18}$ Ralph A. Dungan. Memorandum for the President, 28 August 1963, Brazil: August 1963, National Security File, John F. Kennedy Library.

${ }^{19}$ UNITED STATES SENATE. Nomination of Lincoln Gordon to be Assistant Secretary of State for Inter-American Affairs, p.45.

${ }^{20}$ UNITED STATES SENATE. Nomination of Lincoln Gordon to be Assistant Secretary of State for Inter-American Affairs, p.34.

${ }^{21}$ Gordon não mencionou que uma unidade militar simultaneamente prenderia Miguel Arraes, o governador de Pernambuco, de esquerda. Removendo os dois governadores que simbolizavam a mobilização à direita e à esquerda, Goulart desejaria conferir ao estado de sítio um caráter de neutralidade política. SKIDMORE. Politics in Brazil, 1967, p.263.

${ }^{22}$ UNITED STATES SENATE. Nomination of Lincoln Gordon to be Assistant Secretary of State for Inter-American Affairs, p.35.

${ }^{23}$ Ver a citação na epígrafe deste artigo.

${ }^{24}$ GORDON, L. "Talk for a Princeton Conference on Intervention and Developing States," Nov. 11, 1967. Office of the President, Speeches and Statements, Lincoln Gordon, 1967-68, Series 10, Box 1, Lyndon B. Johnson Oral History Project, p.18-19.

${ }^{25}$ BINDER, D. "U.S. Assembled a Force in 1964 For Possible Use in Brazil Coup," New York Times, Dec. 30, 1976, p.7.

${ }^{26}$ GORDON, L. “Made in Brazil: The 1964 Revolution”. Manuscript. Jan. 1977, p.3-6.

${ }^{27}$ LEACOCK, R. Requiem for revolution: the United States and Brazil, 1961-69. Kent (Ohio): Kent State University Press, 1991.

${ }^{28}$ GORDON, L. "US-Brazilian Reprise," Journal of Interamerican Studies and World Affairs, v.32, n.2, Summer, 1990, p.169.

${ }^{29}$ GORDON, L. A segunda chance do Brasil: a caminho do primeiro mundo. São Paulo: Ed. Senac, 2002.

${ }^{30}$ GORDON, L. Entrevista concedida a James N. Green e Abigail Jones, Washington (DC), 3 ago. 2005, gravada.

${ }^{31}$ GORDON. “Talk for a Princeton Conference on Intervention and Developing States”, p.18-19.

${ }^{32}$ GORDON. “Talk for a Princeton Conference on Intervention and Developing States”, p.18-19.

${ }^{33}$ Ver, FICO, C. O grande irmão: da Operação Brother Sam aos anos de chumbo; o gover- 
no dos Estados Unidos e a ditadura militar brasileira. Rio de Janeiro: Civilização Brasileira, 2008.

${ }^{34}$ GORDON, L. Lincoln Gordon Oral History, March 27, 1964. Kennedy Oral History Project, John F. Kennedy Library.

${ }^{35}$ UNITED STATES SENATE. Nomination of Lincoln Gordon to be Assistant Secretary of State for Inter-American Affairs, p.44.

${ }^{36}$ BINDER, D. "U.S. Assembled a Force in 1964 for Possible Use in Brazil Coup". The New York Times, Dec. 30, 1976, p.7.

${ }^{37}$ UNITED STATES SENATE. Nomination of Lincoln Gordon to be Assistant Secretary of State for Inter-American Affairs, p.7-8.

${ }^{38}$ UNITED STATES SENATE. Nomination of Lincoln Gordon to be Assistant Secretary of State for Inter-American Affairs, p.8.

${ }^{39}$ GORDON, L. "Talk for a Princeton Conference on Intervention and Developing", p.1819.

${ }^{40}$ Lecture at Scarritt College, Nashville, TN 23 Oct. 1968, Office of the President, Speeches and Statements, Lincoln Gordon, 1968-69, Series 10, Box 1, Lyndon B. Johnson Oral History Project.

41 "Ex-U.S. Aid joins protest to Brazil: Gordon and other experts assail faculty purges". The New York Times, 1 June 1969, p.24.

${ }^{42}$ GREEN, J. N. "Clergy, exiles, and academics: opposition to the Brazilian military dictatorship in the United States, 1964-1974", Latin American Politics and Society, v.45, n.1, 2003, p.87-117.

${ }^{43}$ DELLA CAVA, R. “Torture in Brazil”, Commonweal 62, n.6, Apr. 24, 1970, p.129ss.

${ }^{44}$ GORDON, L. "Letter to the Editor", Commonweal 62, n.14, Aug. 7, 1970, p.378.

${ }^{45}$ DELLA CAVA, R. "Reply”, Commonweal 62, n.14, Aug. 7, 1970, p.398.

Artigo recebido em fevereiro de 2009. Aprovado em fevereiro de 2009. 